Contract No. and Disclaimer:

This manuscript has been authored by Savannah River Nuclear Solutions, LLC under Contract No. DE-AC09-08SR22470 with the U.S. Department of Energy. The United States Government retains and the publisher, by accepting this article for publication, acknowledges that the United States Government retains a non-exclusive, paid-up, irrevocable, worldwide license to publish or reproduce the published form of this work, or allow others to do so, for United States Government purposes. 
SRNS-E3100-2010-00008

Proceedings of the $16^{\text {th }}$ International Symposium on the Packaging and Transportation of Radioactive Materials

PATRAM 2010

October 3-8, 2010, London, England

\title{
RADIATION LEVEL CHANGES AT RAM PACKAGE SURFACES
}

\author{
Erich Opperman \\ Savannah River Nuclear Solutions \\ Aiken, South Carolina \\ Ashok Kapoor \\ DOE EM-45 Office of Packaging \\ and Transportation Safety \\ Washington DC
}

\author{
Mark Hawk \\ Oak Ridge National Laboratory \\ Oak Ridge, Tennessee \\ Ronald Natali \\ R.B. Natali Consulting, Inc. \\ Richmond, Utah
}

\begin{abstract}
This paper will explore design considerations required to meet the regulations that limit radiation level variations at external surfaces of radioactive material (RAM) packages. The radiation level requirements at package surfaces (e.g. TS-R-1 paragraphs 531 and 646) invoke not only maximum radiation levels, but also strict limits on the allowable increase in the radiation level during transport. This paper will explore the regulatory requirements by quantifying the amount of near surface movement and/or payload shifting that results in a $20 \%$ increase in the radiation level at the package surface. Typical IP-2, IP-3, Type A and Type B packaging and source geometries will be illustrated. Variations in surface radiation levels are typically the result of changes in the geometry of the surface due to an impact, puncture or crush event, or shifting and settling of radioactive contents.
\end{abstract}

\section{INTRODUCTION}

Radiation level requirements at or near radioactive material package surfaces are governed not only by the maximum allowable values (e.g., $2 \mathrm{mSv} / \mathrm{h}$ ) but also limitations in the amount of variation that is allowed (i.e., $<20 \%$ ). This requires that packaging designs carefully couple the radioactive contents with the structure and geometry of the packaging design to ensure that relative motion between the content and packaging surfaces are minimized. The radioactive content is the source of the penetrating radiation that is present at the package surface. Movement or shifting of contents within the packaging, or settling due to vibration, will result in changes in the radiation levels at the package surface. Similarly a change in the geometry of the package surface due to a drop, impact or crush may also result in unacceptable changes in the radiation level at the deformed surface of the package. It is the responsibility of the package designer to ensure that the radioactive contents and packaging hardware configuration prevents unacceptable changes in the radiation levels. 
This paper uses a number of representative examples commonly used in radioactive material package designs in an approach to explore the dose rate changes at package surfaces. Packages with small concentrated sources, waste boxes and drums with uniformly distributed homogeneous sources as well as more concentrated "point" sources will be examined. The radiation levels will be calculated near the package surfaces using a convienent to use, and commercially available, point kernel shielding code [Ref 1]. The radiation level gradients $(\mathrm{mSv} / \mathrm{h} / \mathrm{cm})$ can then be used to determine the amount of movement required to produce a $20 \%$ increase in the external surface radiation level. Examples of surface deformation due to drop testing as well as radioactive material content movement will be discussed.

The scope of the evaluations and regulations considered are limited to surface transport of packages carrying solid RAM so as only to consider 0.3 to $1.2 \mathrm{~m}$ drops. Additionally readers should use the cases presented in this paper as order-of-magnitude representations of the changes expected in dose rates at package surfaces. The variables in a RAM package are many and this evaluation considers only simplified cases.

\section{REGULATORY REQUIREMENTS}

The radiation level requirements in the IAEA Safety Standards TS-R-1, 2009 [Ref 2] are used in this evaluation. The requirements governing the limits on changes in surface radiation levels will be cited for industrial packages (IP), Type A and Type B. The evaluations look only at the requirements governing radiation level changes at package surfaces, and not the maximum limits.

IP-2, IP-3 and Type A Packages. The applicable requirements for IP-2, IP-3 and Type A packages include the general requirements of para 606-616 and the applicable design and testing requirements specified in 634-647. This includes the effects of accelerations and vibrations associated with routine conditions of transport, as well as the free drop tests specified in 722. Under these conditions the package shall be "designed to prevent more than a 20\% increase in the maximum radiation level at any external surface of the package."

Alternative IP-2 and IP-3 Requirements. There are alternative methods for meeting the IP requirements listed in para 624-628 that include satisfying the UN Packing Group I or II tests; meeting a minimum test pressure of $265 \mathrm{kPa}$ for Tank containers; meeting the ISO 1496-1 design and testing standard for Freight containers; and meeting UN Packing Group I or II tests for metal Intermediate Bulk containers. In all of the above alternative approaches the packages must be designed so that when subject to the specified tests (and routine transport and handling as applicable) the "design would prevent more than a 20\% increase in the maximum radiation level at the external surface of the package."

Type B Packages. Type B packages are designed to meet the general requirements of para 606-616, the design and testing requirements of para 634-647 and additionally the Type B requirements in para 651-664. This includes the Type A requirement in para 646 that the "design would prevent more than a $20 \%$ increase in the maximum radiation level at the external surface of the package" when subjected to normal condition tests - that 
includes the 0.3-1.2m free drop test. Under the Type B hypothetical accident tests the package "would retain sufficient shielding to ensure that the radiation level at $1 \mathrm{~m}$ from the surface would not exceed $10 \mathrm{mSv} / \mathrm{h}$."

All of the regulations sited above have one common theme; the design of the package shall prevent more than a $20 \%$ increase in the maximum radiation level at the external surface of the package. The design, which consists of the radioactive material content and packaging hardware, is to prevent the increase under the routine conditions of transport that include vibrations and accelerations as well as the drop conditions associated with normal handling.

\section{APPROACH}

The radiation level or "dose rate" gradients resulting from hypothetical Cs-137 RAM source materials within content will be calculated near typical package surfaces (e.g., drums, boxes) and the amount of movement (of RAM content or the external surface) required to produce a $20 \%$ increase will be explored. The following case examples will explore the surface radiation level increase for a -

- 205 liter drum uniformly compressed down $15 \mathrm{~cm}$ from top,

- point source in a 205 liter drum

- 2550 liter waste box with uniformly distributed RAM contents

- small special form source package

- settling of RAM contents due to drop testing or vibration

Based on drop test results, actual packaging surface deformation values will be compared to the calculated movements required for a $20 \%$ increase in dose rate. There are three areas of consideration 1) deformation of the outer surface of the package due to drops, 2) internal movement or shifting of the RAM content, and 3) settling of uniformly distributed RAM content due to routine transport vibrations.

\section{CASE EXAMPLES}

Case 1. Drum with uniform RAM content and crushed from top (axially). The first case explores a $205 \mathrm{~L}$ drum filled with zero density and $1 \mathrm{~g} / \mathrm{cc}$ uniformly distributed RAM content that hypothetically drops and is uniformly compressed $15 \mathrm{~cm}$ as shown in Figure 1. The deformation results in a more concentrated RAM content (e.g. radiation source) with increased density ( 1 to $1.22 \mathrm{~g} / \mathrm{cc}$ ). A $0.04 \mathrm{TBq}$ source of Cs-137 is uniformly distributed within the drum. The zero density RAM content case simulated a very light weight payload and the $1 \mathrm{~g} / \mathrm{cc}$ case simulates a heavy weight payload $(220 \mathrm{~kg})$.

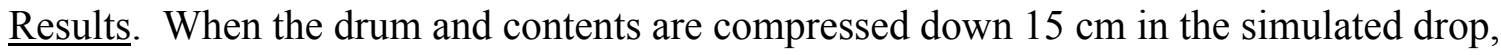
the radiation levels at the top surface of the light and heavy content drums increase by approximately $19 \%$ and $8 \%$ respectively. The radiation level of the light weight drum increases more because the source becomes concentrated without a corresponding significant increase in source density. As the radiation escapes from the volume of the contents, the content itself provides shielding. This "self-shielding" becomes increasingly important as content density increases. Hence the radiation level changes 
due to surface deformation will be smaller for high density heavy content weight drums than for light weight low density content.

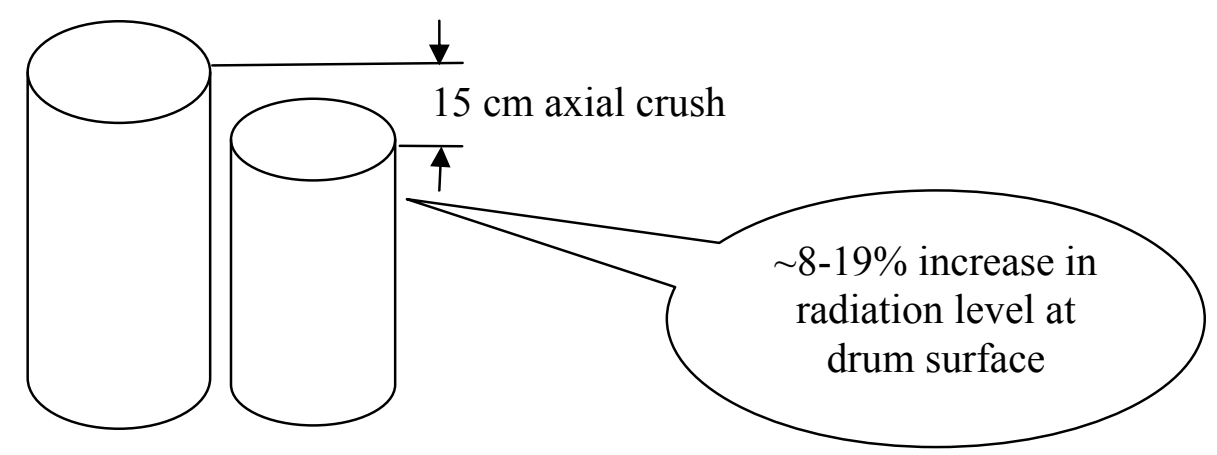

Figure 1. Case 1 depicts the drum with uniformly distributed content compressed in the axial direction $15 \mathrm{~cm}$.

Figure 2 shows the dose rates versus distance from the top of the drum for the light and heavy content cases. Figure 3 shows the change in the radiation level at the drum surface as a function of crush depth. Deformations in excess of $15 \mathrm{~cm}$ for low density content is required before the radiation level at the package surface exceed the regulatory $20 \%$ limit. In reality actual drum deformations due to normal condition drops are more on the order of $2-8 \mathrm{~cm}$ and localized at the edge of the drum as shown in Figure 4. In conclusion for uniform RAM contents in $205 \mathrm{~L}$ drums (that remains uniformly distributed), drop deformation should not result in $20 \%$ increases surface radiation levels.

Case 2. Point source in a 205 liter drum. A 0.04 TBQ point Source of Cs-137 is centered in a $205 \mathrm{~L}$ drum as shown in Figure 7 . The source is surrounded by dunnage having a $1 \mathrm{~g} / \mathrm{cc}$ density. The dose rate gradient is calculated near the surface of the drum to determine the movement necessary to produce a $20 \%$ increase in dose rate. Two cases are considered; one with a shielded drum and one without.

Results. Based on the calculated dose rate gradients shown in Figure 5 it requires $\sim 3 \mathrm{~cm}$ of surface movement to result in a $20 \%$ change in the dose rate. This means that surface deformation toward the source of greater than $3 \mathrm{~cm}$ would result in a $20 \%$ increase in the radiation level. Similarly if the source shifts during transportation within the drum greater than $3 \mathrm{~cm}$ the radiation level at the surface would increase by more than $20 \%$. Figure 6 is a plot of the movement required to produce a 20\% increase in radiation level versus distance from the point source. As shown in Case 1, drums experience local deformations of approximately $2-8 \mathrm{~cm}$ in center of gravity $(\mathrm{CG})$ over corner drops. It is therefore feasible that radiation levels could increase by $20 \%$ for a point source secured in a drum. Sources should be secure within the drum so they do not shift and drum content weight and wall thickness should be designed so that deformation will not exceed $\sim 3 \mathrm{~cm}$. 


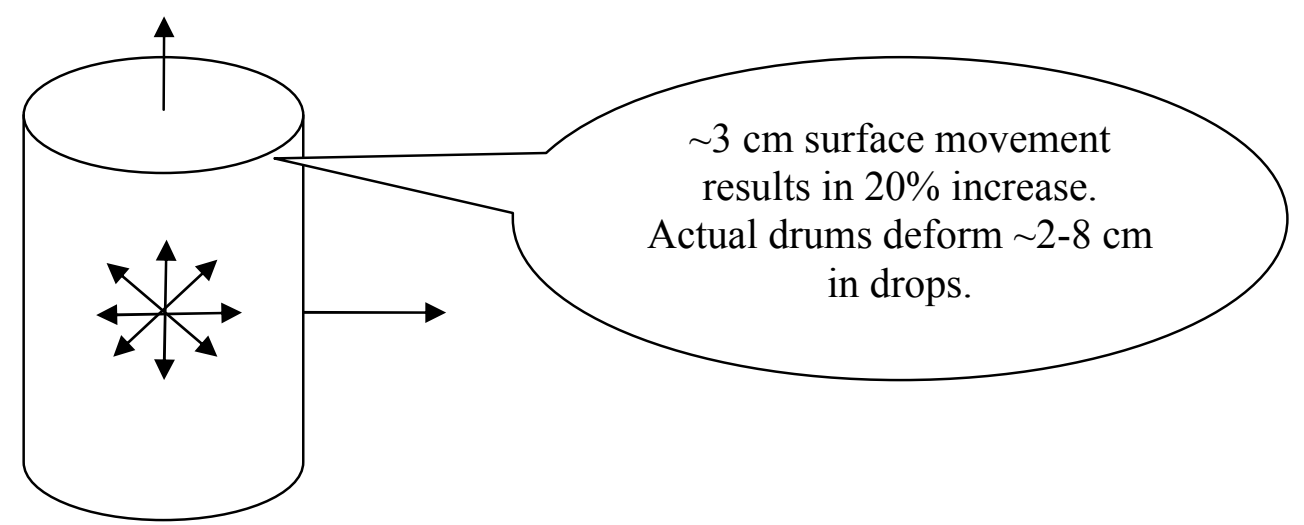

Figure 7. Case 2 is a Point Source in a 205 liter drum.

Case 3. 2550 liter waste box with uniformly distributed RAM content. Case 3 explores a $2550 \mathrm{~L}$ waste box filled with a uniformly distributed $1 \mathrm{~g} / \mathrm{cc}$ content $(2550 \mathrm{~kg})$ as shown in Figure 12. The dose rate gradients are calculated normal to the side wall and at a diagonal away from the corner in line with CG over corner. A source of $0.04 \mathrm{TBq}$ of Cs137 is uniformly distributed within the box. The dose rate gradients are evaluated to determine the motion required to produce a $20 \%$ dose rate increase.

Results. Due to the relatively large waste box source volume the dose rate gradients are more gradual near the surface as shown in Figure 8. The radiation levels are lower along the diagonal as compared to the side wall because the corner is farther away from the centroid of the source volume. Movements on the order of $\sim 10 \mathrm{~cm}$ are required to increase the radiation level by $20 \%$ as shown in Figure 9. Corner deformation in testing is a function of payload weight and physical form, and box stiffness. A stout reinforced corner may deform only a few $\mathrm{cm}$, whereas lower strength boxes may deform well beyond $10 \mathrm{~cm}$. See Figures $10 \& 11$. To prevent surface dose rates from increasing beyond $20 \%$ at waste box corners designers should ensure that corners are sufficiently stiff and that payload shifting will be minimal. The latter is problematic as loose payload is often carried in low level waste boxes.

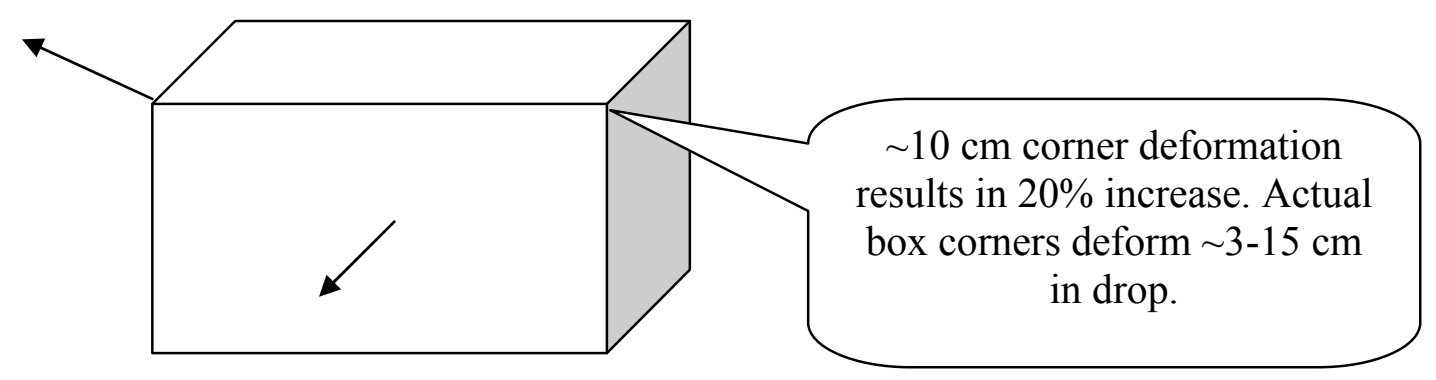

Figure 12. Case 3 is a uniform source in 2550 liter waste box ( $2550 \mathrm{~kg}$ content weight).

Case 4. Small special form source package. Case 4 explores a $5 \mathrm{~cm}$ dia uniform source within a shielded package having an outer diameter of $40 \mathrm{~cm}$ as shown in Figure 13. This case simulates a typical Type A special form source package. The dose rate gradients are 
calculated near the external package surface to determine the amount of movement that results in a $20 \%$ dose rate increase.

$\underline{\text { Results. }}$ Based on the calculated dose rate gradients shown in Figure 14 an approximate $2 \mathrm{~cm}$ of surface movement is required to result in a $20 \%$ change in the dose rate. As shown in Figure 15 only $\sim 2 \mathrm{~cm}$ movement is required to produce a $20 \%$ change in dose rate, source packagings must be designed to be robust with tight tolerances and to securely house the radioactive source capsule.

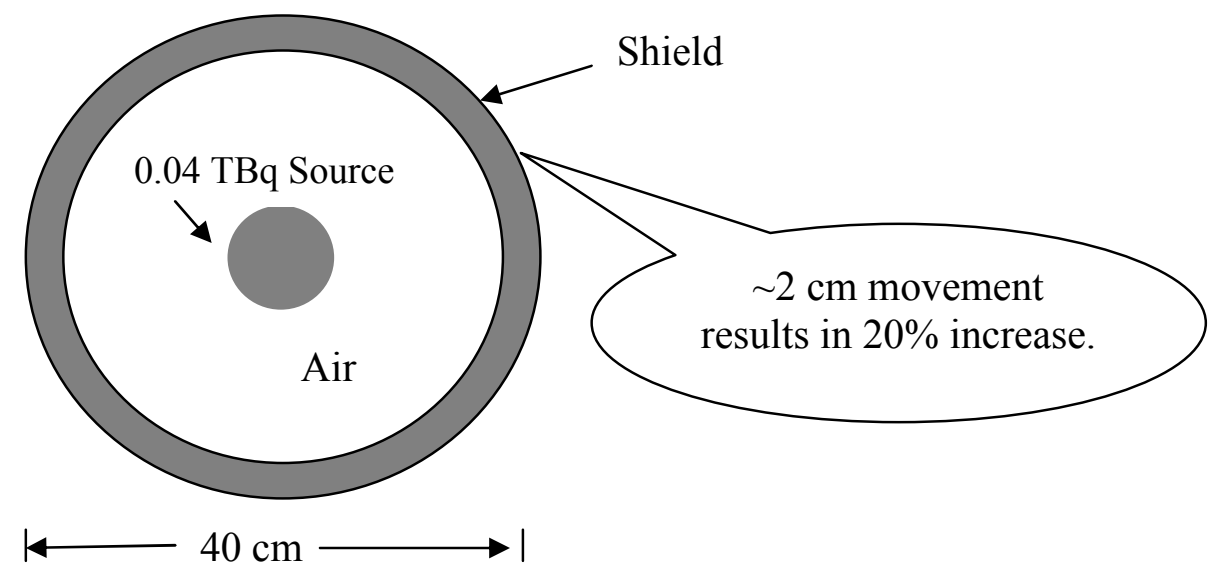

Figure 13. Case 4 is a small special form source package.

Case 5. Settling of RAM contents due to drops or vibrations. Case 5 explores the settling of loosely packed RAM content in a waste box as shown in Figure 16. This simulates content settling that may occur during transportation due to drops or vibrations. As the payload settles the source term becomes more concentrated and its density increases. The dose rate gradients are calculated near the side wall of the package at locations of maximum dose rate. A uniformly distributed $0.05 \mathrm{TBq}$ source is uniformly distributed through out the content volume. The dose rate gradients are calculated near the external package surface to determine the amount of movement that results in a $20 \%$ dose rate increase. The waste boxes are modeled as 2550 liter boxes with 0.5 and 0.1 $\mathrm{g} / \mathrm{cc}$ content densities which represent typical "heavy" and "light weight" payload weights of 1250 and $255 \mathrm{Kg}$ respectively.

Results. As the RAM contents settle for the heavy payload case the maximum dose rate at the side was changes only slightly. However, for the light weight content cases, the dose rate increases significantly. For the light weight case the maximum dose rate increases $\sim 15 \%$ when the payload settles to $75 \%$, and increases $30 \%$ when the payload settles to $50 \%$ of the original volume. Figure 17 show the dose rate gradients near the side wall for the two payload densities. These results are similar to Case 1 for the compressed drum. When contents are sufficiently dense external dose rate increases are minimal because increases in self-shielding due to payload compression off setting the higher radioactive source density. For lower density contents the self-shielding factor is less important. It can be concluded that significant payload settling will increase surface 
dose rates by more than $20 \%$. It is emphasized that these are simplistic calculations for hypothetical cases. In reality radioactive source material is seldom truly uniformly distributed in solid payloads.

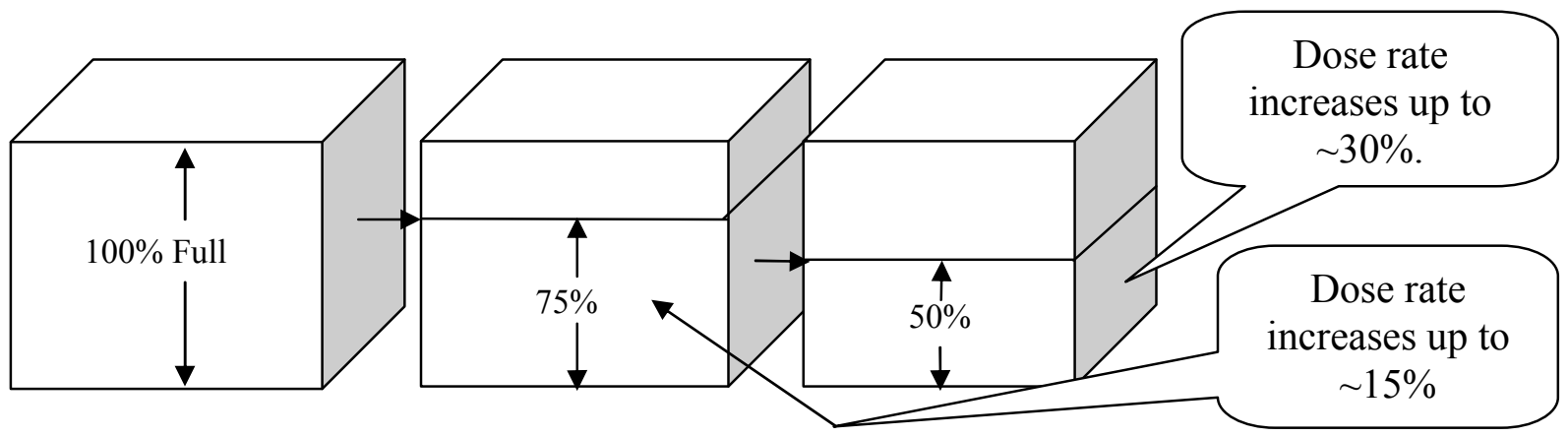

Figure 16. Case 5 depicts radioactive payload settling due to transportation drops or vibrations.

\section{CONCLUSIONS}

Surface radiation level increases in excess of $20 \%$ may occur in radioactive material packages due to shifting contents or outer packaging wall deformations. Smaller RAM packages with concentrated RAM sources (e.g. capsules) have relatively steep dose rate gradients at the package surface so these packaging designs must ensure that the source is well secured against internal movement (e.g., $<2 \mathrm{~cm})$ and that the outer packaging is robust to minimize surface deformation in drop considerations. Larger volume packages such as drums or boxes carrying uniformly distributed RAM (e.g., low level waste) have smaller surface dose rate gradients due to the physically large source volume. For these packages surface deformations on the order of $\sim 10 \mathrm{~cm}$ are required to produce radiation level increases of $20 \%$. In practice, drums typically do not deform in excess of $10 \mathrm{~cm}$, however waste boxes dropped CG over corner may well exceed deformations of $10 \mathrm{~cm}$. Additionally drop tests will result in the payload shifting in the direction of the impact which can also increase surface radiation level.

Payload settling may also result in surface radiation level increases in excess of $20 \%$. For the idealized cases looked at in this paper, if a light weight content settles to $50 \%$ of its original volume, the maximum surface dose rate will increase $\sim 30 \%$. This clearly exceeds the required $20 \%$. As payloads increase in weight the effect of settling is much less pronounced due to the increase in self-shielding within the content volume. The cases in this paper consider only idealized content and source distributions. In reality the distribution of RAM within a package is often non-homogeneous. There are often "hot spots" or zones of higher dose rates present. In these cases the package designer along with the shipper must carefully consider the methods for payload securement so RAM content movement is minimized during handling and transit.

The package designer is responsible for ensuring that the packaging and associated RAM contents are well engineered to minimize relative movement within the packaging during transport. The shipper is very important as it is the shipper's responsibility to ensure that not only the packaging is properly loaded and that the RAM contents are adequately 
SRNS-E3100-2010-00008

blocked, braced and secured against movement but the entire package assembly is properly secured to the conveyance.

\section{ACKNOWLEDGMENTS}

The authors greatfully acknowledge review comments provided by Steven J. Nathan and Teresa M. Davis of Savannah River Nuclear Solutions, LLC, and Angela McGee of UTBattelle, LLC, Oak Ridge National Laboratory.

\section{REFERENCES}

1. MicroShield ${ }^{\circledR} 7$, Grove Software, Inc. 147 Mill Ridge Road, Lynchburg, VA 24502, www.radiationsoftware.com.

2. TS-R-1, Regulations for the Safe Transport of Radioactive Material, International Atomic Energy Agency (IAEA), 2009 Edition. 


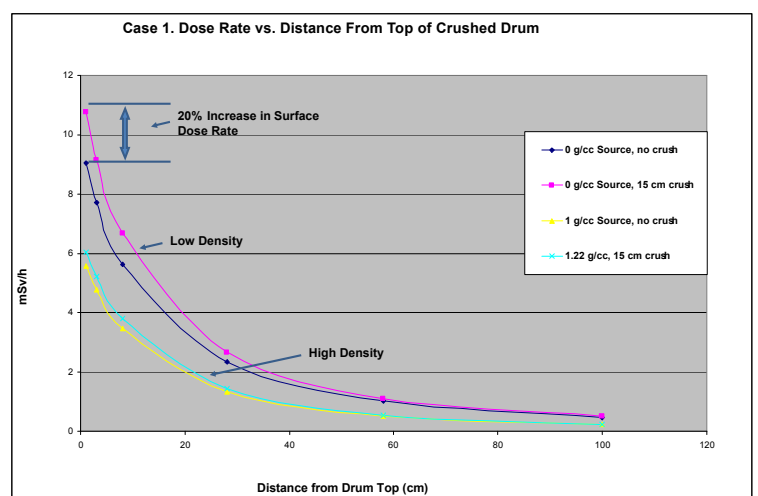

Figure 2. Dose rate vs. distance from drum top for low and high content density.

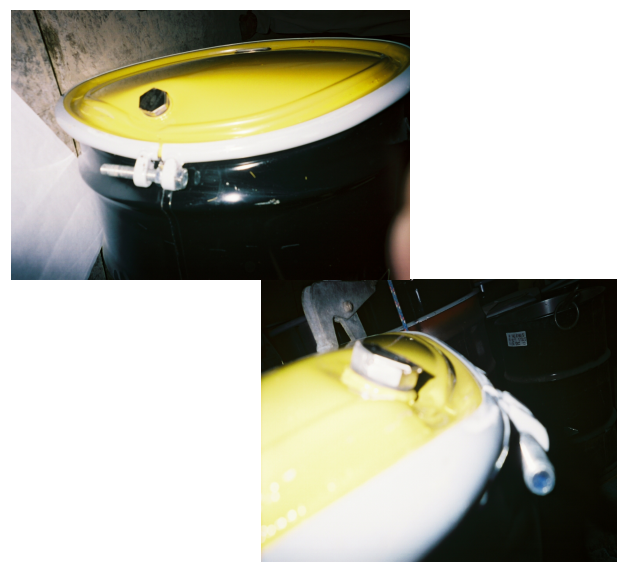

Figure 4. Actual drum deformation from $1.2 \mathrm{~m}$ drop with $430 \mathrm{~kg}$ content.

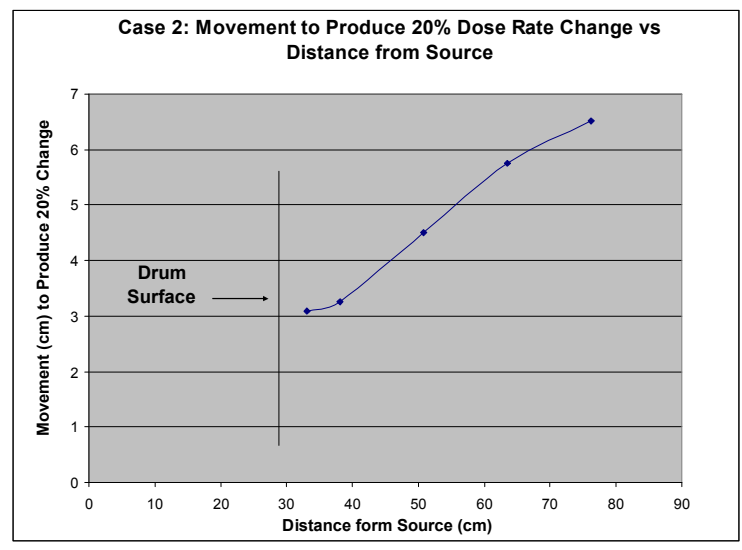

Figure 6. Movement $(\mathrm{cm})$ to produce $20 \%$ dose rate change vs. distance from drum.

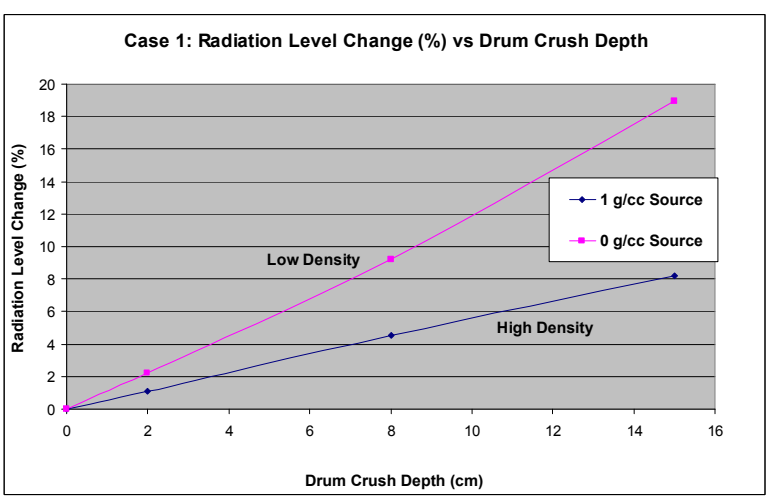

Figure 3. Percent change in dose rate vs. drum crush depth $(\mathrm{cm})$.

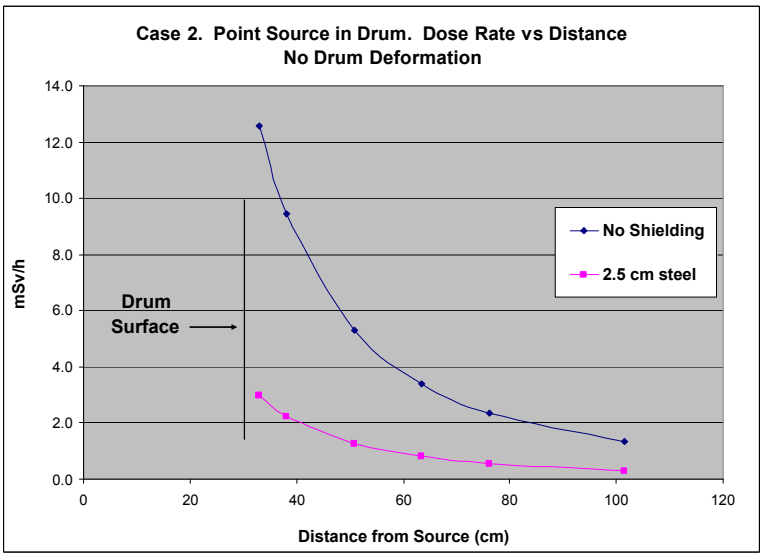

Figure 5. Dose rate gradients vs. distance from drum surface.

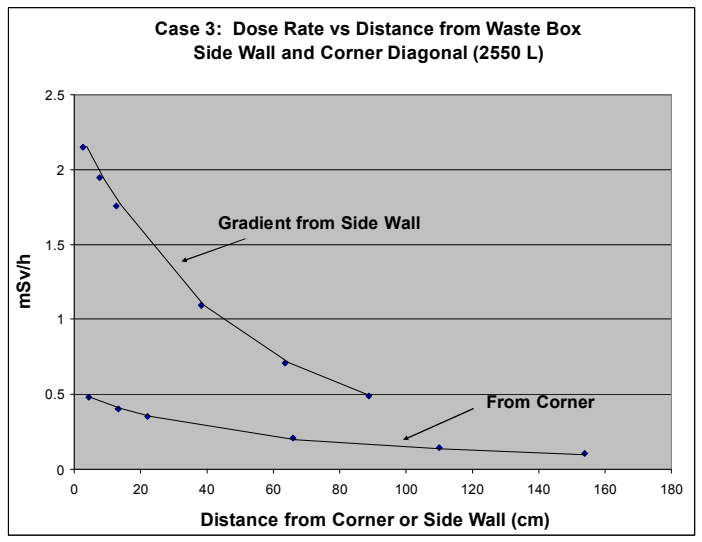

Figure 8. Dose rate vs. distance from box side wall and corner. 


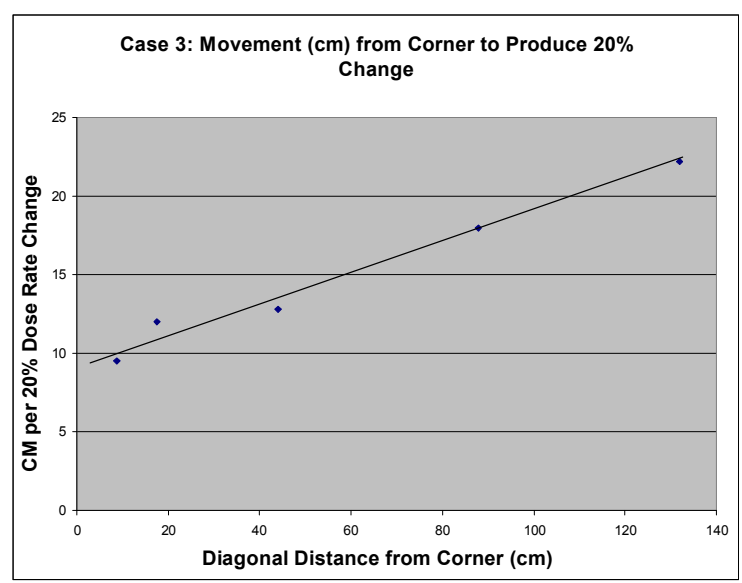

Figure 9. Movement from corner to produce $20 \%$ dose rate change.

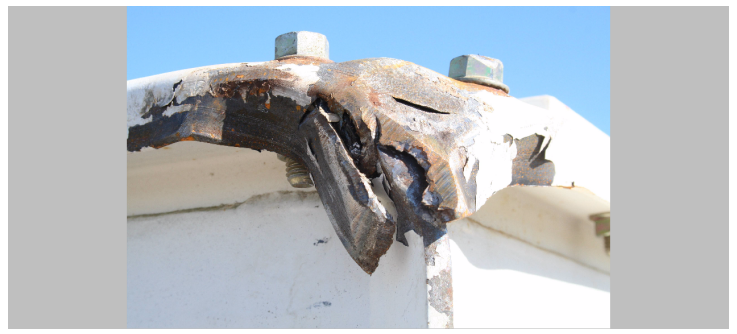

Figure 11. Deformation in waste box after $\mathrm{CG} /$ corner $1.2 \mathrm{~m}$ drop (minor deformation).

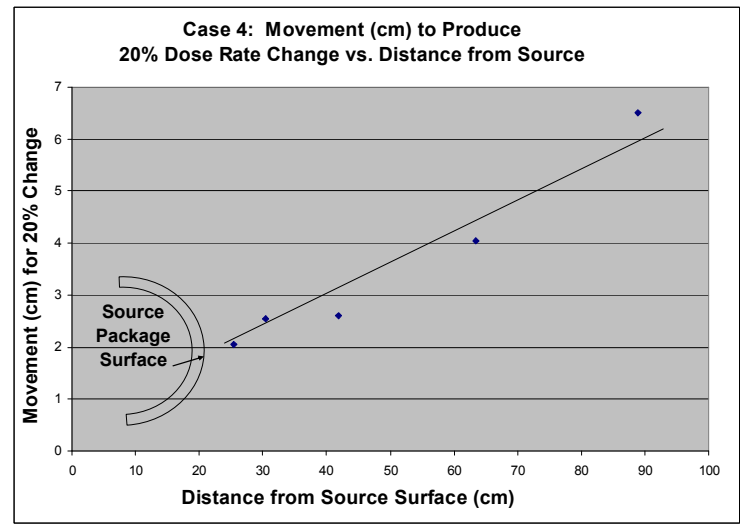

Figure 15. Movement to produce $20 \%$ change vs. distance from source.

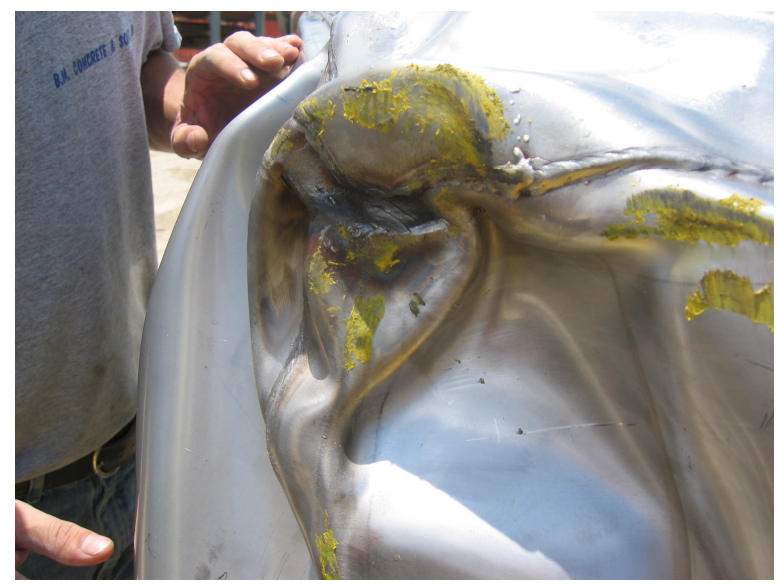

Figure 10. Deformation in waste box after CG/corner $1.2 \mathrm{~m}$ drop (major deformation).

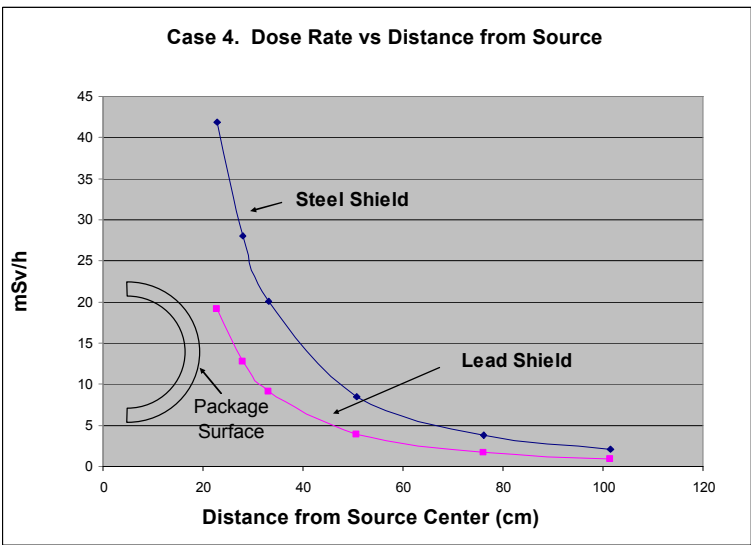

Figure 14. Dose rate vs. distance from source package.

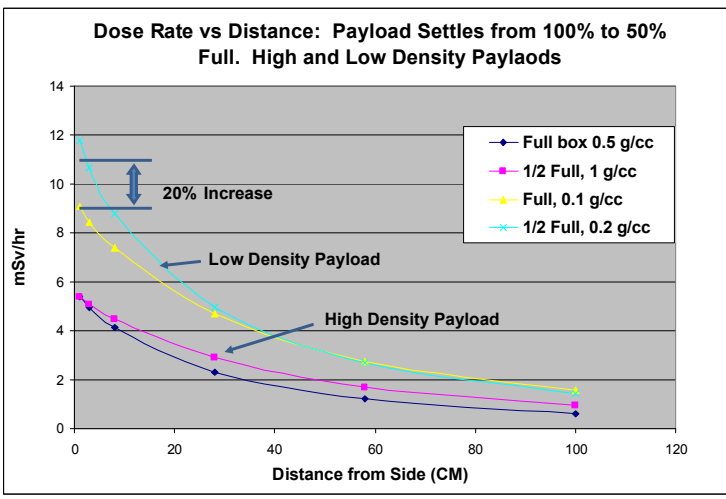

Figure 17. Dose rate vs. distance from side of box as payload settles. 